\title{
(t)
}

\section{CONSELHOS E SUAS: AVANÇOS NO FORTALECIMENTO DA CULTURA DE DIREITOS}

\author{
Councils and SUAS: improvements for strengthening \\ a culture of rights
}

\section{Angela Vieira Neves ${ }^{1}$ Marlene de Jesus Silva Santos ${ }^{2}$}

\section{RESUMO}

O presente artigo propõe discutir as possibilidades de construção de uma cultura política de direitos na garantida de uma cidadania ativa com a implementação do SUAS nos diferentes municípios brasileiros, a partir das deliberações realizadas nos conselhos de políticas de Assistência Social. Chamamos a atenção para a importância dos conselhos gestores, criados, inovadoramente, pela Constituição de 1988, como instâncias deliberativas na efetivação desta política. Argumenta-se que, sem nos reportarmos à relação entre culturas políticas que são colocadas em xeque no Brasil, fragiliza-se o SUAS enquanto um sistema descentralizado e participativo. Este é o desafio da proposta.

PALAVRAS-CHAVE

Assistência Social. Conselhos de Direito. Cultura Política.

\footnotetext{
${ }^{1}$ Assistente Social, Doutora em Ciências Sociais, Professora do Programa de Pós-Graduação em Política Social e do Departamento de Serviço Social da Universidade de Brasília. E-mail: <angelaneves@unb.br>.

${ }^{2}$ Professora da Universidade de Brasília. Assistente social e Mestre em Política social pela Universidade de Brasília, Professora do Departamento de Serviço social da Universidade de Brasília. E-mail: <marlenedjss@unb.br>.
} 


\section{ABSTRACT}

This article aims to discuss the possibilities of building a political culture of rights guaranteed in an active citizenship with the implementation of SUAS in the different Brazilian municipalities, based in the discussions in the social assistance councils. We emphasize the importance of policy management councils, innovatively created by the 1988 Constitution, as deliberative and effective spaces where the system of social assistance policy is strengthened defended. We argue that without questioning the types of political cultures that are in opposition in Brazil we undermine SUAS as a decentralized and participatory system. This is the challenge of this proposal.

\section{KEYWORDS}

Social Assistance Councils. Social Assistance policy. Political Culture.

Submetido: 13/3/2012

Aceito: $14 / 5 / 2012$

\section{INTRODUÇÃO}

A sociedade brasileira inaugura, com a Constituição de 1988, o Estado Democrático de Direito. O termo pareceria corriqueiro, considerando que grande parte das democracias capitalistas europeias há muito utilizam a presente forma de organização do Estado. Contudo, é preciso atentar que, para cada realidade histórica, há um processo político que lhe traduz e o formato democrático da citada constituição significou um salto inovador para a realidade do país.

O Brasil viveu anos de reprodução de uma cultura clientelista e patrimonialista, nas palavras de Carvalho (2003), a atuação na administração pública era considerada uma vocação de todos. Nisso, seguia-se que a profissionalização e, principalmente, a construção democrática de políticas públicas teve pouco espaço na história de formulação de ações estatais no Brasil.

A política de assistência social, por seu turno, pode ser apresentada como um exemplo emblemático deste processo inovador de democratização inaugurado com a Constituição de 1988. Historicamente, voltada ao atendimento aos indivíduos alijados do acesso ao mercado de trabalho, no Brasil, só adquiriu o status de política pública a partir da Constituição, tendo 
sido, até então, operada pela via do favor e como importante moeda política (BRASIL, 1988).

Este artigo dará atenção a este processo de transformação e de disputa entre duas culturas políticas, uma existente desde os primórdios do descobrimento do Brasil, e outra inaugurada e positivada com a Constituição de 1988. O entendimento do texto é que a superação do clientelismo não acontece instantaneamente e, mesmo após o texto constitucional, as práticas políticas reproduzem-no no cotidiano, entretanto, tencionadas por novas práticas que tentarão instituir uma nova lógica de ação democrática.

Chama-se atenção à herança conservadora que atravessa o Estado Brasileiro por meio de mecanismos que representam uma retração aos avanços dos direitos e da primazia do Estado no trato da coisa pública em detrimento da dimensão privatista.

No caso da assistência social, além do simples fato de que o Estado passa a ser o responsável pela prestação das ações e não somente o setor privado, outro instrumento é de importante papel neste processo de substituição da cultura do favor pela cultura democrática: os conselhos de assistência social.

Argumenta-se que os conselhos de assistência social, como espaços deliberativos, podem trazer ao Estado a manifestação do poder e da vontade popular, radicalizando o que se entende por participação democrática. A ação dos conselhos mostra-se fundamental na transformação da assistência social em política pública, não só nominada no texto legal, mas operada na prática cotidiana do Sistema Único de Assistência Social (SUAS). Chama-se atenção que a participação da sociedade erigiu este sistema que será tanto mais democrático, quanto maior se fortalecerem os conselhos como instâncias de efetiva participação social qualificada e atuante.

\section{NOTAS INTRODUTÓRIAS SOBRE A CULTURA POLÍTICA BRASILEI- RA E ASSISTÊNCIA SOCIAL}

A Seguridade Social é um conjunto articulado e integrado de ações de iniciativa dos poderes públicos e da sociedade, destina-se a assegurar, adicionalmente, os direitos relativos à saúde, à previdên- 
cia e à assistência social. Esse marco histórico institui, legalmente, a completude legal da cidadania no Brasil, com a garantia à população de direitos sociais, políticos e civis, sob a ordem do Estado democrático de direito. Contudo, todo marco legal efetiva-se no cotidiano da sua implementação.

Sabe-se que a definição legal não garante a prática real. A cidadania, pela simples nominação, não transforma a realidade desigual da sociedade capitalista. É pela ação dos sujeitos políticos que as bases da desigualdade e da pobreza são colocadas em xeque, e os direitos são conquistados e se tornam realidade para os cidadãos. Isso é ainda mais patente no caso do Brasil, onde se reproduzem traços de clientelismo e patrimonialismo, uma cultura política completamente avessa à consolidação de direitos e efetivação da democracia. Por isso a Constituição de 1988, na sua juventude, apresentou ao Brasil o grande desafio de construir uma nova prática política que se inclui a sociedade civil nas decisões das políticas.

Esta cultura política pautada em aspectos antidemocráticos permeia todos os campos de vida social e também as políticas públicas, incluída a política de assistência social, como o mais jovem componente do sistema de seguridade social. Isto posto, interessa-nos analisar os avanços já construídos nesta política pública, principalmente os que se referem à sua perspectiva democrática e participativa, e os desafios de sua consolidação nos espaços prioritários que são os Conselhos de Assistência Social.

Nesse sentido, é importante destacar que essa cultura política tem raízes no nosso país e foi traçada na desigualdade e na concentração de renda e de poder na mão de poucos. Isso é revelado no que Sales (1994, p. 26) diz, ao enfatizar que a "[...] cultura política da dádiva sobreviveu ao domínio privado das fazendas e engenhos coloniais, sobreviveu à abolição da escravatura, principalmente no compromisso coronelista e chegou até nossos dias."

Nosso país foi marcado por uma tradição autoritária e excludente que se caracteriza, como afirmou Dagnino (1994, p.105), por um autoritarismo social, que "[...] engendra formas de sociabilidade e uma cultura autoritária de exclusão que subjaz ao conjunto das práticas sociais e reproduz a desigualdade nas relações sociais." 
Essas questões atravessam as práticas políticas e têm relação com a assistência social na qual o clientelismo aparece como uma mediação fundante entre o Estado Brasileiro e a sociedade. Portanto, a relação entre clientelismo e assistência social não é nova na cultura política brasileira. É sabido que o fenômeno do clientelismo aparece como fator predominante da política brasileira ao ordenar as relações sociais entre diferentes classes, em especial, no que concerne à população mais pobre. Roberto Da Matta (1984) enfoca essa questão, ao destacar a clássica pergunta: "Você sabe com quem está falando?”, que é emblemática desta prática política discriminatória e perversa que persiste em uma sociedade fundada em relações autoritárias.

Na sociedade brasileira, os clássicos da história do Brasil nos revelam a gênese da formação sociopolítica, evidenciando as ambiguidades e complexidades presentes na política brasileira. Desde a década de 1930, há afirmações na literatura de que o clientelismo se constitui por relações de subordinação à dita elite e de troca de favores entre os dominantes, principalmente, latifundiários, prevalecendo o que Sales (1994, p.27) identificou como "[...] cultura política da dádiva [...]”, que marca, definitivamente, uma formação social em que os direitos são travestidos em favores. A autora ressalta, ainda, que, na cultura política brasileira, "[...] ou bem se manda ou bem se pede". Está no simples conteúdo desses dois verbos o significado mais profundo de nossa cultura política do mando e da subserviência.

Nessas análises, identificam-se, na literatura, diferentes formatos do clientelismo que perpassam a sociedade brasileira e moldam as relações políticas nelas imbricadas. Para Diniz (1982), existem dois modelos de clientelismo: o primeiro se fundamenta em um clientelismo de tipo tradicional, personalista. O segundo é caracterizado por dimensão mais coletiva presente nas instituições políticas de caráter religioso, corporativo e/ou profissionais. O clientelismo atravessa diferentes contextos sociopolíticos, persistindo e sendo ressuscitado em formas distintas daquela construída sob a oligarquia.

Segundo Neves (2008), as diferentes conceituações sobre o clientelismo são abordadas a partir de três questões que convergem na literatura. A primeira é o entendimento do clientelismo para além 
de simples troca material e/ou econômica. Vai-se além dessa análise, pois é visto como troca simbólica: ajuda, influência e poder. A segunda é a compreensão do clientelismo como relação de subordinação entre elite e massa, entre dominantes e dominados. Uma terceira conceituação abordada na literatura o coloca como uma relação que é um complemento, preenchida pelo vazio (gap) deixado pelo Estado. Esses aspectos são relevantes para o aprofundamento do conceito, constituindo três questões: troca material; troca simbólica, complemento (preenche as lacunas deixadas pelo vazio deixado pelo Estado).

Em suma, dois tipos foram característicos: o chamado clientelismo tradicional, identificado pelo seu caráter personalista e privado, e o clientelismo mais institucional, de caráter coletivo, presente nos grandes partidos e nas mobilizações políticas de suas lideranças.

O clientelismo, portanto, existe desde a colonização e persistiu mesmo em contextos autocráticos que buscavam a racionalidade técnica do Estado, uma vez que ele seria mantido para conservar as elites no poder e, em particular, para perpetuar lideranças políticas por meio da distribuição de recursos em troca de apoio político.

De fato, o clientelismo está presente na sociedade brasileira desde o século XIX; as relações desenvolvidas pelos políticos constituem uma prática clientelista mediante trocas de favores e de acordos. Em estudo a respeito dessa prática, Graham (1997, p. 15) mostra que: "[...] o clientelismo constituía a trama de ligação da política no Brasil do século XIX e sustentava virtualmente todo ato político".

A relação entre clientelismo e assistência social não é nova na cultura política brasileira. Essa questão perpassa quotidianamente as práticas políticas, sendo uma relação intrínseca com a assistência social no Brasil. Se analisarmos de forma breve o histórico da assistência social no Brasil, constataremos sua vinculação com a ideia de favor e caridade em que:

[...] as primeiras formas de assistência social no Brasil se desenvolveram dentro de um contexto histórico, a partir dos anos 30, que marcou o Estado como o principal ator e interventor junto à assistência social no país, que aparece fundamentada dentro do conceito de benevolência, voluntarismo e filantropia. $\mathrm{O}$ 
Estado, a partir deste período, institucionalizou os serviços voluntários, travestindo-os como doação e caridade ao povo, mascarando-se os direitos de cidadania (NEVES, 1994, p. 20).

A assistência social sempre foi pensada como área menor, residual, campo da tutela aos usuários, política Ad-Hoc. Por outro lado, a partir da constituição federal de 1988, a Assistência marca sua trajetória como política pública e dever do Estado enquanto direito dos cidadãos. Nesse sentido, para pensarmos a relação entre assistência social e clientelismo na atualidade, é necessário atentar para que tipo de cultura política se enfrenta no cotidiano da política. Para isso, devemos pensar a relação entre público e privado no Estado Brasileiro e as relações por eles engendradas.

Este ambiente político começa a ser transformado após a Constituição-Cidadã de 1988 (BRASIL, 1988) quando institui a impessoalidade como princípio de ação do Estado Brasileiro e inicia o processo de democratização da sociedade. Esta proposição legal, contudo, não nos permite afirmar que o clientelismo tenha sido superado e totalmente extinto na sociedade brasileira, mas que ele apresenta-se de maneira mais competitiva e moderna nas organizações do Estado na contemporaneidade. Particularmente sobrevive na Política de Assistência social e se materializa numa nova tensão em que a prática política é constituída por seus atores na imbricada relação entre clientelismo e direitos.

Isto permite observar, ainda, a coragem da constituinte na instituição da ideia de seguridade social. Em um país no qual, até então, a figura do seguro resguardava o que, em muitos casos, foi chamado cidadania regulada (SANTOS, 1979), a constituição amplia de forma peculiar o público de acesso às políticas sociais, promovendo, ineditamente, o aceso à saúde por meio de um sistema único universal e da assistência social para quem dela necessite.

\section{ASSISTÊNCIA SOCIAL E CLIENTELISMO: UMA PERVERSÃO À CUL- TURA DE DIREITOS}

A Seguridade Social rompe não só com a lógica dos seguros, mas, principalmente, com a histórica e intrínseca relação entre clientelismo e assistência social, traços perversos à democracia e à consolidação de direitos sociais. 
A assistência social garantida no Artigo 203 da Constituição (BRASIL, 1988), componente da Seguridade Social, tem o evidente foco nos incapazes ao trabalho, contudo, discretamente, produz uma inflexão no público atendido pela via não previdenciária com a instituição do Benefício de Prestação Continuada (BPC) ${ }^{3}$, hoje um dos maiores investimentos de assistência social, cujos dados de julho de 2011 apontam um montante acima de 13 bilhões (BRASIL, 2011a) investidos em pagamentos de benefícios.

Não resta dúvida a potencialidade da política de assistência social no enfrentamento das iniquidades sociais brasileiras. Entretanto, em uma sociedade conservadora cujo primado do trabalho assalariado suplanta o da proteção social, a previsão legal institui um espaço institucional a ser preenchido, mas não sem muita luta política e disputa.

A primeira destas lutas enfrentada pela assistência social foi a sua regulamentação, hoje realizada na Lei Orgânica de Assistência Social (LOAS) ${ }^{4}$ (BRASIL, 1993). Efetivada somente cinco anos depois da promulgação constitucional, o primeiro texto da lei foi reprovado 5 pelo então presidente da república Fernando Collor de Mello sob a alegação de que o BPC, embora previsto na Constituição, se mantido no texto da LOAS, seria: “[...] abono familiar, com características de complemento de renda familiar, [é] incompatível com os fins da assistência social" (CÂMARA DOS DEPUTADOS, 1990 apud BOSCHETTI, 2006).

Isso fez do primeiro texto letra morta, protelando a realização do previsto constitucionalmente. Esta discussão tomou forma mais democrática posteriormente, balizada em um amplo debate político que envolveu um conjunto de intelectuais, representantes governamentais, militantes e categoria profissional de assistentes sociais. Essa mobilização política permitiu, sob outro momento político, já no Governo Itamar Franco, a política

\footnotetext{
3 "Art. 203. A assistência social será prestada a quem dela necessitar, independentemente de contribuição à seguridade social, e tem por objetivos: [...] V - a garantia de um salário mínimo de benefício mensal à pessoa portadora de deficiência e ao idoso que comprovem não possuir meios de prover à própria manutenção ou de tê-la provida por sua família, conforme dispuser a lei (BRASIL, 1988). ${ }^{4}$ Neves (1994) mostra, na sua dissertação de mestrado, as dificuldades da aprovação da LOAS no contexto do governo Collor nos anos 90.

${ }^{5}$ Neves (1994) mostra, na sua dissertação de Mestrado, as dificuldades da aprovação da LOAS no contexto do governo Collor nos anos 90.
} 
de assistência social ganhar o formato descentralizado e participativo que operacionalizaria a previsão constitucional anterior (BOSCHETTI, 2006).

Deste marco histórico em diante, a operacionalização da LOAS torna-se o campo de disputa constante entre a lógica do assistencialismo e da garantia do direito, ou seja, entre a lógica do direito e a filantropia privada presente na assistência social com um caráter forte na cultura política nessa área.

A definição legal cria, assim, um novo desafio, que é consolidar uma nova relação entre público e privado no cotidiano da operacionalização do direito à assistência social.

Nesse aspecto, seguindo a argumentação do Grupo de Estudos sobre a Construção Democrática (GECD):

$$
\begin{aligned}
& \text { [...] a indistinção entre público e privado, subja- } \\
& \text { cente a uma concepção oligárquica da política, } \\
& \text { onde os interesses privados assumem precedência } \\
& \text { sobre o interesse público, está no centro de uma } \\
& \text { matriz básica que continua presidindo a configura- } \\
& \text { ção da sociedade brasileira, e em relação à qual as } \\
& \text { instituições políticas de democracia representati- } \\
& \text { va liberal se acomodaram sem rupturas significati- } \\
& \text { vas (GRUPO DE ESTUDOS SOBRE A CONSTRUÇÃO } \\
& \text { DEMOCRÁTICA, 1998-1999, p. 45-46). }
\end{aligned}
$$

Caracteriza-se, assim, a cultura privatista do Estado Brasileiro por meio de traços conservadores na tradição histórica da sociedade brasileira, como o patrimonialismo, o fisiologismo, o nepotismo, a corrupção e o fenômeno do clientelismo. Nesse aspecto, o clientelismo se expande no Estado e não consegue separar a relação pessoal e patrimonial entre o que se define como interesse privado e interesse público. Para Martins (1994, p.38) “[...] certamente é essa disseminada prática que associa patrimônio e poder a principal responsável pela difusão e contínua renovação do que pode ser chamado de [...] cultura da apropriação do público pelo privado"

A despolitização do público pela indistinção com o privado é cada vez mais presente na conjuntura atual. O projeto neoliberal não só despolitiza as ações coletivas, como também desmo- 
biliza a sociedade civil ${ }^{6}$ e desconstrói direitos e lutas até então conquistados pelas classes populares, pelos trabalhadores, em uma privatização do espaço público e em uma refilantropização das questões sociais, em que direitos são travestidos em carências e favores.

A relação entre público e privado no Estado Brasileiro sempre foi alvo de debates, críticas e estudos desde os mais progressistas aos mais conservadores. O que passa a ser consenso a partir de 1988, contudo, é que o Estado deve se democratizar dar transparência de suas decisões e, principalmente, descentralizar suas ações.

No campo da assistência social, começa-se pela desvinculação da assistência social da previdência social, superando a histórica justaposição (BOSCHETTI, 2003), caracterizada pela dependência financeira e institucional da primeira com relação à segunda. Seguido pela construção de um modelo descentralizado e participativo que vem sendo materializado no SUAS no sentido de combater o clientelismo e a filantropia privada muito forte nessa área.

Contudo, é preciso não perder de vista que a conjuntura na qual se constrói o SUAS é bastante adversa e que ele emerge como uma forma de resistência na luta da assistência como política pública e enquanto direito social. Ele representa a tentativa de romper, superar e/ou alterar a tradição histórica presente na sociedade brasileira, como o clientelismo, que limita as práticas políticas do Estado e seus gestores na busca da construção de uma cultura pública, participativa e coletiva.

\footnotetext{
${ }^{6}$ Para Gramsci (2001, p. 20), sociedade civil é "[...] o conjunto de organismos designados vulgarmente como 'privados' [...]”, formada pelas organizações responsáveis tanto pela elaboração quanto pela difusão das ideologias, compreendendo assim o sistema escolar, as igrejas, os sindicatos, os partidos políticos, as organizações profissionais, a organização material da cultura (que se dá pelos jornais, revistas, editoras, meios de comunicação de massa), etc. Em suma, os ditos aparelhos privados de hegemonia - organismos sociais coletivos voluntários e relativamente autônomos em face da sociedade política (GRAMSCI, 2004). Assim, a sociedade civil é considerada uma das esferas principais do Estado visto em seu sentido ampliado; a outra é a sociedade política, ou seja, o conjunto de mecanismos por meio dos quais a classe dominante detém o monopólio legal da repressão e da violência, e que se identifica com os aparelhos de coerção sob controle das burocracias executivas e policial-militar).
} 


\section{O SUAS E A IMPLEMENTAÇÃO DO SISTEMA DESCENTRALIZADO E PARTICIPATIVO}

O SUAS é o capítulo mais recente e também tem se mostrado o mais profícuo na efetivação da assistência social como política pública. Instituído pela Política Nacional de Assistência Social (PNAS), contida na Resolução $n^{\circ} 145$ do Conselho de Assistência Social, de 15 de outubro de 2004 (CONSELHO NACIONAL DE ASSISTÊNCIA SOCIAL, 2004), não significa uma mera operativa legal, mas um amplo processo de discussão social cujo resultado coletivo se apresenta na normativa vigente.

Marco de regulamentação da Lei Orgânica de Assistência Social, a PNAS de 2004 é o passo inicial no processo normativo de operacionalização de uma nova era na prestação da política de assistência no Brasil. Seguida pela Norma Operacional Básica do SUAS (NOB/ SUAS) (BRASIL, 2005), Norma Operacional de Recursos Humanos ((NOBRH/SUAS) (BRASIL, 2009a), Tipificação de Serviços do SUAS (CONSELHO NACIONAL DE ASSISTÊNCIA SOCIAL, 2009) e, finalmente, pela Lei do SUAS (BRASIL, 2011). É importante destacar que o SUAS inova em diferentes aspectos da política pública.

Na NOB/SUAS (BRASIL, 2005), traduz-se para estados e municípios uma estrutura administrativa operacional da prestação da política pública de assistência social enquanto dever do estado e direito da sociedade. Rompe com o improviso e a urgência, introduzindo como ponto central o planejamento e monitoramento do gasto público em forma de um sistema descentralizado e participativo. Impactou, ainda, instituindo instâncias públicas de operação da assistência social: os Centros de Referência da Assistência Social (CRAS) e os Centros de Referência Especializada da Assistência Social (CREAS). Estas instâncias públicas tornam-se emblemáticas da presença pública na área de assistência e aliadas à rede privada de serviços, seja ela filantrópica seja vocacional, compõem a prestação de serviços do SUAS. Nisso, coloca-se ao Estado sua responsabilidade operativa rompendo com lógicas operativas de contratos e convênios com o privado.

A NOB/RHSUAS, deita normatização para fazer contraponto ao histórico do "primeiro-damismo" na política de assistência. Como argumenta Torres (2002), a presença das primeiras-damas como 
gestoras das ações de assistência social, remonta à criação da Legião Brasileira de Assistência Social (LBA). Tal instituição, criada com fins assistencialistas para prover necessidades das famílias de militares envolvidos em representação ao Brasil na Segunda Guerra, torna-se emblemática da operação clientelista de políticas assistencialistas pelas primeiras-damas como prática recorrente na história brasileira.

É assim que - como amiúde já se observou - o trabalho da LBA afirmou a figura da primeira-dama no Brasil, 'possivelmente numa extensão do populismo peronista argentino como sustentáculo das ações sociais públicas' (FALCÃO, 1990, p. 154).

Disso deduz-se que, no imaginário das classes subalternas, as primeiras-damas representam papéis que evocam generosidade e caridade humana. São representações mentais marcadas por sentimentos isentos de criticidade, em uma experiência de dependência e de passividade. Na verdade, a relação de dominação, sob o véu do paternalismo que as primeiras-damas mantêm com os usuários dos serviços sociais, constitui uma face cruel da opressão que conduz à passividade, tratando esses usuários como seres dependentes desse tipo de serviço (TORRES, 2002, p. 93).

Conforme situa a autora, a política de assistência social prestada enquanto simples ação social esteve permeada por aspectos de desprofissionalização e uso político. Esta situação vai ser rompida pelo SUAS. Começa-se com a NOB/SUAS ao exigir a gestão pública responsável, seguida pela $\mathrm{NOB} / \mathrm{RH} / \mathrm{SUAS}$, que exige a profissionalização da assistência social, rompendo com o histórico clientelista, patrimonial. Nisso, impõe equipe mínima de atuação, a todos os aparelhos públicos, como CRAS e CREAS, e sugere a profissionalização em todo o sistema único de assistência na construção, ainda que embrionária, de uma nova cultura política de direitos.

Os documentos de tipificação e a regulamentação dos CRAS e CREAS auxiliam na operação municipal do SUAS, direcionando um padrão de qualidade de prestação de serviço nacional Ação, contudo, plenamente adaptada à realidade municipal, posto que a territorialidade é princípio básico do SUAS. Assume-se a responsabilidade pública pela qualidade do serviço na perspectiva 
da matricialidade sociofamiliar (CONSELHO NACIONAL DE ASSISTÊNCIA SOCIAL, 2004), com prestação de serviços profissionais com qualidade e forma definidas.

Em resumo, o SUAS é desenho que traduz o Art. $1^{\circ}$ da LOAS:

Art. $1^{\circ} \mathrm{A}$ assistência social, direito do cidadão e dever do Estado, é Política de Seguridade Social não contributiva, que provê os mínimos sociais, realizada através de um conjunto integrado de ações de iniciativa pública e da sociedade, para garantir o atendimento às necessidades básicas (BRASIL, 1993).

O SUAS consegue efetivar, na normativa, as perspectivas democrática e participativa, rompendo com a histórica ausência de diretrizes e dificuldades operacionais que sempre acompanharam a política de assistência social. Uma normativa que, embora fria quando apenas apresentada em folhas de papel, significa um processo árduo de discussão nacional integrada pela participação de conselhos estaduais e municipais de todo o país.

O que vai diferenciar o SUAS de qualquer outra normativa é o seu potencial democrático, um importante sinal daquilo que se espera da política de assistência social que: garanta o atendimento das necessidades básicas dos indivíduos que dela necessitem.

A discussão coletiva do SUAS materializada no preâmbulo da Resolução 145/2004, que aprova o texto da Política Nacional de Assistência Social, conforme segue, aponta o primeiro êxito do SUAS, transformando a política de assistência social de clientelista em participativa e democrática (CONSELHO NACIONAL DE ASSISTÊNCIA SOCIAL, 2004):

MINISTÉRIO DO DESENVOLVIMENTO SOCIAL E COMBATE À FOME

CONSELHO NACIONAL DE ASSISTÊNCIA SOCIAL

RESOLUÇÃO N 145, DE 15 DE OUTUBRO DE 2004 (DOU 28/10/2004)

O Conselho Nacional de Assistência Social - CNAS, considerando a apresentação de proposta da Política Nacional de Assistência Social - PNAS pelo Ministério do Desenvolvimento Social e Combate a Fome - MDS em 23 de junho, considerando a realização de Reuniões Descentralizadas e Ampliadas do Conselho 
para discussão e construção coletiva do texto final da PNAS ocorridas respectivamente em 21 e 22 de julho de 2004 na cidade de Aracaju e em 21 e 22 de setembro de 2004, no Distrito Federal e, considerando o disposto no artigo 18, incisos I, II, IV da Lei 8.742 de 7 de dezembro de 1993, RESOLVE:

Art. $1^{\circ}$ - Aprovar, em reunião do Colegiado de 22 de setembro de 2004, por unanimidade dos Conselheiros a Política Nacional de Assistência Social.

Art. $2^{\circ}$ - Aprovar, na reunião do Colegiado de 14 de outubro de 2004, por unanimidade dos Conselheiros o texto final discutido e elaborado pelo grupo de trabalho - GT/PNAS constituído pela Resolução N..$^{\circ} 78$, de 22 de junho de 2004, publicada no D.O.U., de 02 de julho de 2004.

Art. $3^{\circ}$ - O texto da Política Nacional aprovado constituirá o Anexo I da presente Resolução.

Art. $4^{\circ}$ - Revogam-se as disposições em contrário.

Art. $5^{\circ}$ - Esta Resolução entra em vigor na data de sua publicação.

MARCIA MARIA BIONDI PINHEIRO

Presidente do CNAS

Nesse aspecto, é importante destacar o papel fundamental dos Conselhos de Assistência Social. Presentes em todos os níveis de gestão, a sua participação no processo de discussão da política nacional e de toda a normativa do SUAS representa um avanço e potencializa democraticamente a assistência social. Fator inédito e potencial, tendo em vista o histórico de clientelismo presente na área Política de Assistência Social.

Isso nos mostra que, apesar de possuir um histórico avesso à cidadania o Brasil, começa o desenvolvimento de uma Cultura de direitos. A partir dos anos 80, uma jovem democracia, uma sociedade civil ressurge no Brasil, colocando em xeque essa cultura política do favor com o aparecimento de espaços públicos no sentido de fortalecer o Estado democrático de direitos e a cidadania.

A LOAS e, posteriormente, o SUAS vão fortalecer a expansão dos conselhos gestores de política como espaço de controle democrático da política pública. Presentes em todos os municípios brasileiros, os conselhos de assistência social são hoje chamados por todas as normativas do SUAS a fiscalizar e garantir a operação da 
assistência social enquanto direito de cidadania. Contudo, disso surgem outras questões, em especial, sobre as características da representação da sociedade civil, e os interesses políticos reproduzidos nos conselhos de assistência social.

\section{O PAPEL DOS CONSELHOS GESTORES NO FORTALECIMENTO DA POLÍTICA DE ASSISTÊNCIA SOCIAL}

Para analisar o papel da sociedade civil neste processo, é preciso observar os aspectos históricos. A partir da segunda metade dos anos 70, novos canais de participação social se constituíram em um campo de confronto à Ditadura, permitindo e possibilitando maior abertura à participação no final da década de 80. É na denúncia ao autoritarismo do Estado, no contexto da Ditadura, e como alternativa aos espaços tradicionais de luta - como sindicatos e partidos políticos - que se qualifica a sociedade civil como espaço político de resistência e de luta por melhores condições de vida.

Essa participação popular emerge no seio dos movimentos populares dos anos 80 com caráter reivindicativo dentro de um campo movimentalista, reforçando o projeto democrático (DOIMO, 1995). O termo participação tornou-se palavra de ordem para a esquerda, multiplicando-se em experiências de participação em alguns municípios.

Nos anos 80, a participação social e coletiva tinha caráter mais reivindicativo no controle social sobre o Estado junto aos movimentos sociais urbanos, estando de costas para o Estado num confronto acirrado na luta por melhoria das condições sociais. Já nos anos 90, ela é deslocada em virtude da confluência dos projetos e do enfrentamento em diferentes culturas políticas, que vão desenhando novo tipo de participação, a qual pode ou não ser despolitizada pelo projeto neoliberal.

A Constituição Federal de 1988 (BRASIL, 1988) - conhecida como Constituição-Cidadã - ao reafirmar instrumentos importantes para a democratização do Estado, mostrou-se decisiva para a publicização do orçamento e do Estado. Pela primeira vez, uma constituição retrata a importância da construção de um Estado Democrático de Direitos. Ao estimular a participação da sociedade civil por meio de outros mecanismos, tais como o Plebiscito, o Referendo e a inicia- 
tiva popular, como em uma democracia semidireta, nos termos de Benevides (1998), ressalta-se a importância da participação da população na implementação de Políticas Públicas, inovando e gerando forte expectativa quanto à construção do projeto democrático.

É nos marcos da hegemonia do Projeto Neoliberal - particularmente, no Governo Collor de Mello, em 1989 - que, coincidentemente, esses espaços públicos participativos se multiplicaram. Interessante notar que as experiências participativas ganharam notoriedade com o início da implementação do projeto neoliberal. Nos anos 90, a participação deixa de ser um confronto ao Estado para se caracterizar como "participação negociada" na disputa entre projetos distintos, em processo de cogestão entre o Estado e a sociedade, nesses novos espaços públicos. Duas questões são destacadas nessa época: um processo de procura por novos direitos - direito a ter direitos na construção de uma cidadania ativa e a participação das classes populares na gestão participativa da cidade, buscando a construção de uma cultura participativa.

De um lado, o redirecionamento, a despolitização e a desmobilização da ação foram a marca do projeto neoliberal, enquanto, de outro, assistiu-se a um boom de experiências de gestão democrática e participativa. Nesse cenário em que a Constituição é promulgada, são feitas alterações importantes nos marcos da construção de um Estado de direito e de um processo democrático, no qual municípios foram criados e novos instrumentos de gestão, como os conselhos gestores, se multiplicam.

No entanto, durante os anos 90 - em particular, com o projeto $\mathrm{Ne}$ oliberal - a sociedade civil passa a ser vista de outra forma, estando então associada ao mercado. Esse ocultamento do significado democratizador da sociedade civil deve ser um ponto importante para a análise do potencial deliberativo dos conselhos de Assistência Social no Brasil.

Esses arranjos participativos que eclodiram no final dos anos de 1990 e hoje já estão consolidados institucionalmente precisam ser mais bem qualificados e aceitos na partilha do poder de decisão junto ao Estado; esse é o grande desafio para fortalecer o Estado democrático de direito. 
O objetivo dos conselhos de direito, dentre eles o de assistência social, é colaborar com a construção de uma cultura pública de direitos, colocando em xeque a forma de se fazer política no Brasil baseada em relações meramente privadas e corporativas nas quais a coisa pública é tratada como algo privado. A literatura tem apontado muitas dificuldades nessa relação entre Estado e Sociedade civil, principalmente na partilha do poder de decisão, em que se busca dar transparência aos gastos públicos.

Segundo dados do Instituto Brasileiro de Geografia e Estatística (IBGE) - Perfil dos Municípios Brasileiros (IBGE, 2009) -, o país conta hoje com 5.565 municípios. No que se refere aos Conselhos de Assistência Social, quase todos os municípios brasileiros (99,3\%) possuíam Conselho Municipal de Assistência Social. Em 2005, eram 98,8\%. Em relação à composição dos conselhos, houve aumento dos não paritários. Entretanto, 58,0\% detinham maior representação da sociedade civil em 2009. Sobre o caráter deles, registra-se decréscimo na proporção de municípios com conselhos deliberativos (de 94,8\%, em 2005, para 91,6\%, em 2009).

Essa ampliação institucional, de um lado, representa um avanço para o fortalecimento da esfera pública e do controle democrático. Por outro, torna-se o maior desafio para o fortalecimento das políticas sociais públicas, particularmente a política de assistência social frente à cultura privatista do Estado Brasileiro e da exclusão da sociedade civil nos processos de decisão no Brasil desde os anos de 1930 até 1988. A Constituição Federal representou um divisor de águas na luta pelos direitos sociais, pela afirmação e pela consolidação da Seguridade Social, em particular, da Política de Assistência Social.

Porém, a implementação legal não garante por si só o seu fortalecimento porque depende da relação entre a cultura política existente nas práticas do Estado e da própria sociedade civil na ruptura com práticas antidemocráticas - aqui destacamos o clientelismo e patrimonialismo do Estado brasileiro no uso do dinheiro público. Uma das principais dificuldades no desenvolvimento de uma cultura pública de direitos é a vontade do governo em entender que esse é o melhor caminho para garantir a democracia, as decisões públicas no sentido da transparência e 
partilhar o poder de decisão com a sociedade civil, fortalecendo o SUAS e sua operacionalidade com os CRAS e CREAS. Nesse aspecto, o diálogo com os conselhos gestores de Assistência Social são fundamentais para o fortalecimento dessa nova cultura política de direitos, que, com o SUAS, emerge tencionando essa cultura clientelista historicamente marcada pela filantropia e pelo favor na Assistência Social.

É importante lembrar que a PNAS foi instituída em 2004, como resolução do Conselho Nacional de Assistência Social (CNAS), e dispõe que as ações na área sejam organizadas num sistema descentralizado e participativo, constituído pelas entidades e organizações de Assistência Social, articulando meios, esforços e recursos, e por um conjunto de instâncias deliberativas, compostas pelos diversos setores envolvidos na área (CONSELHO NACIONAL DE ASSISTÊNCIA SOCIAL, 2004).

O SUAS consolida um processo, que envolve, entre outras questões que atravessaram o Conselho Nacional de Assistência Social, a ruptura com a concepção cartorial e corporativa do conselho.

Sobre esta característica é preciso lembrar que o CNAS foi criado em substituição ao antigo Conselho Nacional de Seguridade Social (CNSS) e assume a responsabilidade de emitir, em âmbito federal, certificados de isenção fiscal para entidades privadas componentes da rede de assistência social. Segundo análise de Raichelis (1998), esta atribuição chamada "cartorial" de análise documentação e emissão do chamado Certificado de Entidade Beneficente de Assistência Social (CBAS) 7 trouxe para o CNAS uma dicotomia, ocupando grande parte do espaço de discussão da política pública, mas, ao mesmo tempo, garantindo a consolidação do CNAS enquanto espaço de participação. O CBAS foi a forma de solidificação do conselho enquanto órgão deliberativo de assistência social, mas foi também um importante entrave ao tempo dedicado às efetivas discussões democráticas sobre a política de assistência social.

\footnotetext{
7 Isenção de contribuições para a seguridade social. A certificação das entidades beneficentes de assistência social e a isenção de contribuições para a seguridade social serão concedidas às pessoas jurídicas de direito privado, sem fins lucrativos, reconhecidas como entidades beneficentes de assistência social com a finalidade de prestação de serviços nas áreas de assistência social, saúde ou educação, e que atendam ao disposto nesta Lei.
} 
Esta característica do conselho começa a se transformar a partir da aprovação da PNAS, que já materializa uma superação da função cartorial, apresentando o CNAS como importante espaço de articulação da voz popular que ecoa dos conselhos municipais de assistência. Acompanhando este processo, o CNAS abandona definitivamente suas funções cartoriais com a aprovação da Lei $N^{\circ} 12.101 / 2009$ que muda radicalmente o seu papel enquanto instância de certificação de entidades privadas prestadoras de serviços assistenciais.

A lei define que as entidades beneficentes, antes caracterizadas como de assistência social, agora caracterizar-se-ão em função de sua atividade-fim, a saber: saúde, educação e assistência social. Para tanto, institui parâmetros de definição de cada uma delas e estipula as ações sociais que podem caracterizá-las para recebimento de certificado, que as legitima para isenção fiscal. E, o mais importante, determina que não seja mais no âmbito do CNAS a operação para a concessão do certificado, que se dará, a partir de então, segundo o Artigo 21 da lei, conforme segue:

\section{Seção IV \\ Da Concessão e do Cancelamento}

Art. 21. A análise e decisão dos requerimentos de concessão ou de renovação dos certificados das entidades beneficentes de assistência social serão apreciadas no âmbito dos seguintes Ministérios:

I - da Saúde, quanto às entidades da área de saúde; II - da Educação, quanto às entidades educacionais; e III - do Desenvolvimento Social e Combate à Fome, quanto às entidades de assistência social (BRASIL, 2009, Art. 21).

Em recente livro publicado sobre a Assistência Social e filantropia (PAULA; PAZ; STUCHI, 2010), os autores defendem que é importante destacar o papel das entidades socioassistenciais que sempre estiveram presentes na execução de serviços na área da Assistência Social no Brasil. Embora grande parte delas paute suas ações pela filantropia privada e confessional, não se pode deixar de considerar sua importância na rede de proteção social e também como componentes do SUAS, inclusive conforme previsto na LOAS. Isto indica que, embora a certificação deixe de ser função do CNAS, a histórica presença do setor privado continuará tencionando e sen- 
do importante fator na atuação do Conselho. A esse respeito, Raquel Raichelis (2010) analisa essas contradições e disputas entre as entidades no âmbito do CNAS, e afirma que:

Os embates que cercaram a recente aprovação dessa lei são uma expressão inequívoca das resistências para fazer transitar a Política de Assistência Social para o âmbito da proteção social como obrigação pública e responsabilidade do Estado, ainda que para sua implementação participem as entidades de natureza privada, seja de prestação direta de serviços, socioassistencial, de assessoramento ou defesa de direitos (RAICHELIS, 2010, p. 18)

Com isso, observa-se que a lei reforça o entendimento de que, para romper com a ideia do uso do dinheiro público para fins privados, é necessário o fortalecimento do controle democrático. Só por meio dessa diretriz que os espaços dos conselhos poderão ganhar legitimidade dentro do próprio Estado na luta contra a corrupção, interesses privados e busca de partilhar o poder ao incluir a sociedade civil nas decisões das políticas públicas.

O SUAS prevê a participação, de forma integrada, das entidades socioassistenciais, porém, ressalta-se aqui que essa participação pode enfraquecer o SUAS e a Política de Assistência Social se realizada de forma frágil e se não houver a qualificação dos representantes dessas entidades no tocante à defesa da Política de Assistência Social em sua universalização enquanto política pública.

Fica claro agora que o Conselho de Assistência Social, nascido com o objetivo de romper essa prática clientelista, assistencialista e "cartorial", abandona a prática de emissão de certificados de filantropia com a Lei $N^{\circ} 12.101$ de 2009 que o recoloca no seu devido lugar, ou seja, acompanhar a política de Assistência Social na implementação do chamado controle democrático.

Esta mudança de posição operacional do CNAS (de cartorial a deliberativo) não deveria ser inovadora já que ele nasce com esse objetivo nos anos 90. Contudo, esta transferência do poder de emissão de certificados de filantropia para os diferentes Ministérios por meio de sua tipificação (Assistência Social, Educação e Saúde) cria, no âmbito do Conselho, movimentos contraditórios. O primeiro, construir uma nova cultura política pautada na inovação democrá- 
tica por meio da efetivação do chamado controle democrático, um papel reivindicado desde os anos 90 . O segundo, criar resistências da sociedade civil no âmbito do Conselho, procurando permanecer com a prática política "cartorial" que deu ao conselho um poder muito forte na cultura política brasileira em milhares de municípios de certificar ou não entidades da sociedade civil.

Essa questão parece ser o grande dilema hoje no CNAS, um dilema que se apresenta na luta pela efetivação da política de Assistência Social, e sua afirmação enquanto política pública e no campo dos direitos sociais. Esse dilema representa um desafio na consolidação do conselho na efetivação de seu papel no acompanhamento, fiscalização, monitoramento e avaliação das políticas de assistência social. Fatores tão caros aos gestores públicos e reivindicados pela sociedade civil desde a Constituição Federal desde 1988, tendo sido bandeira de luta dos movimentos sociais e da sociedade civil.

A prática operativa da política e não cartorial no CNAS legitima o entendimento de que o seu papel é controlar e decidir sobre a política pública, com responsabilização ativa do Estado numa perspectiva ética e não gerencial, flexível e privada, nos termos de Pereira (1996).

De todo exposto, fica claro que o diálogo com os conselhos torna-se prioritário hoje na luta por direitos sociais e na construção de uma cultura de direitos em detrimento do interesse particular de grupos corporativos. A cultura do favor só será efetivamente superada pela instituição de uma política pública democrática e participativa. Nisso, os Conselhos Gestores, em especial o CNAS, são agentes fundamentais, desde que munidos da qualificação e ação pautada na cultura do direito e não do favor. O fortalecimento e consolidação do SUAS centra-se em um diálogo fecundo com esses conselhos que hoje assumem seu verdadeiro papel na construção de políticas públicas e no fortalecimento da cultura de direitos em detrimento da ideia de favor historicamente presente na Assistência Social.

\section{CONSIDERAÇÕES FINAIS}

Buscamos, nesse artigo, chamar a atenção para a relação entre o desenvolvimento de uma cultura política de direitos com a imple- 
mentação e consolidação do SUAS nos diferentes municípios brasileiros por meio de um diálogo mais fecundo com os conselhos de Assistência social, espaços públicos fundamentais para garantir o fortalecimento do sistema descentralizado e participativo do SUAS. A dificuldade de ampliar os processos decisórios, incluindo a sociedade civil, exige um esforço em buscar mecanismos de partilha do poder que sejam fundamentais na democratização da política, na efetivação de direitos e tomada de decisões, e, para isso, é necessário qualificar essa participação por meio da representação. O surgimento dos conselhos gestores no contexto da sociedade brasileira nos anos de 1990 tinha como meta combater a corrupção, evitando que o dinheiro público fosse usado para outros fins - que não a construção de políticas públicas. Esses mecanismos foram criados para combater essa cultura privatista do Estado no trato da coisa pública.

Apontou-se que é fundamental estabelecermos alguns parâmetros avaliativos para o desenvolvimento da Política de Assistência Social no Brasil a partir da cultura política existente em diferentes municípios. Isto que dizer que é preciso um olhar mais atento sobre a sociedade civil e seu associativismo, e para os espaços dos conselhos gestores de assistência, na construção de uma nova cultura política voltada para o interesse público e a cultura de direitos. Sem essa atenção, corre-se o risco de cair nas armadilhas Neoliberais, que reforçam o conservadorismo, o atraso centrado na ideia de que o Estado deve ser mínimo para questões sociais e máximo para o capital, e de que a sociedade civil mercantilizada deve substituir o Estado ao invés de controlá-lo. Essa equação não pode ser verdadeira, já que mostramos, nesse artigo, o histórico de lutas, disputas entre projetos e, principalmente, tensão entre culturas políticas, atualmente consolidadas, particularmente na Assistência social. Devemos ficar atentos para as práticas políticas e os elementos que obstaculizam a ideia de direitos, e isso não se dá sem um olhar sobre a cultura política local nos diferentes municípios, sem um aprofundamento e aproximação do diálogo entre conselhos, CRAS e CREAS. Só assim ocorrerá o desenvolvimento de uma nova cultura de direitos fortalecida frente à cultura política clientelista enraizada nas práticas políticas no Brasil seja no Estado seja na sociedade civil. O desafio está posto. 


\section{REFERÊNCIAS}

BENEVIDES, M.V. A Cidadania ativa: referendo, plebiscito e iniciativa popular. 3. ed. São Paulo: Ática, 1998.

BOSCHETTI, Ivanete. Assistência Social no Brasil: um direito entre originalidade e conservadorismo. 2. ed. Brasília: Ed. do Autor, 2003.

BOSCHETTI, Ivanete. Seguridade social e trabalho: paradoxos na construção das políticas de previdência e assistência social no Brasil. Brasília: LetrasLivres: UnB, 2006.

BRASIL. Constituição Federal 1988. Constituição da República Federativa do Brasil. Brasília: Senado Federal, 1988.

BRASIL. Lei $n^{\circ} 12.435$, de 6 de julho de 2011. Altera a Lei no 8.742, de 7 de dezembro de 1993, que dispõe sobre a organização da Assistência Social. Brasília, 2011. Disponível em: <http://www.planalto. gov.br/ccivil_03/_Ato2011-2014/2011/Lei/L12435.htm>.

BRASIL. Lei no 8.742, de 7 de dezembro de 1993. Dispõe sobre a organização da Assistência Social e dá outras providências. Brasília, 1993. Disponível em: <http://www.planalto.gov.br/ccivil_03/leis/ I8742.htm>.

BRASIL. Lei $n^{\circ}$. 12.101, de 27 de novembro de 2009. Dispõe sobre a certificação das entidades beneficentes de assistência social; regula os procedimentos de isenção de contribuições para a seguridade social; altera a Lei no 8.742, de 7 de dezembro de 1993; revoga dispositivos das Leis nos 8.212, de 24 de julho de 1991, 9.429, de 26 de dezembro de 1996, 9.732, de 11 de dezembro de 1998, 10.684, de 30 de maio de 2003, e da Medida Provisória no 2.187-13, de 24 de agosto de 2001; e dá outras providências. Brasília, 2009. Disponível em: <http:// www.planalto.gov.br/ccivil_03/_at02007-2010/2009/lei/l12101.htm>.

BRASIL. Secretaria Nacional de Assistência Social. Coordenação Geral da gestão de benefícios. BPC/LOAS - benefícios ativos em julho de 2011, e recursos gastos no mês e no ano de 2011. Brasília, 2011a. Disponível em: <http://www.mds.gov.br/relcrys/bpc/docs/ downloads/2011/Jultodos.xls>. Acesso em: 11 jul. 2011.

BRASIL. Norma Operacional Básica de Recursos Humanos do SUAS - NOB-RH/SUAS. Brasília: Ministério do Desenvolvimento Social e Combate à Fome, 2009a. 
BRASIL. Norma Operacional Básica NOB/SUAS. Brasília: Ministério do Desenvolvimento Social e Combate à Fome, 2005.

CARVALHO, José Murilo de. A construção da ordem: a elite política imperial. Teatro de sombras: a política imperial. Rio de Janeiro: Brasileira, 2003.

CONSELHO NACIONAL DE ASSISTÊNCIA SOCIAL (Brasil). Resolução no 145, de 15 de outubro de 2004. Aprova a Política Nacional de Assistência Social. Brasília, 2004. Disponível em: <http://www.mds. gov.br/cnas/legislacao/resolucoes/2004>.

CONSELHO NACIONAL DE ASSISTÊNCIA SOCIAL (Brasil). Resolução $n^{\circ} 109$, de 11 de novembro de 2009. Aprova a Tipificação Nacional de Serviços Socioassistenciais. Brasília, 2009. Disponível em: <http://www.mds.gov.br/cnas/legislacao/legislacao/resolucoes/arquivos-2009/resolucoes-normativas-de-2009/>.

DA MATTA, Roberto. A casa e a rua: espaço, cidadania, mulher e morte no Brasil. Rio de Janeiro: Rocco, 1984.

DAGNINO, Evelina. Os anos 90: política e sociedade no Brasil. São Paulo: Brasiliense, 1994.

DINIZ, Eli. Clientelismo urbano: ressuscitando um antigo fantasma?. Novos Estudos CEBRAP, São Paulo, v. 1, n. 4, p. 21-26, 1982.

DOIMO, Ana Maria. A vez e a voz do popular: movimentos sociais e participação política no Brasil pós-70. Rio de Janeiro: ANPOCS, Relume Dumará, 1995.

FALCÃO, M. do Carmo B. C. As primeiras-damas ressurgem na era Collor. Revista Serviço Social \& Sociedade, São Paulo, n. 33, 1990.

GRAHAM, Richard. Clientelismo e política no Brasil do Século XIX. Rio de Janeiro: Editora da UFRJ, 1997.

GRAMSCI, A. Cadernos do cárcere. 2. ed. Rio de Janeiro: Civilização Brasileira, 2001. v. 2.

. 3. ed. Rio de Janeiro: Civilização Brasileira, 2004. v. 3.

GRUPO DE ESTUDOS SOBRE A CONSTRUÇÃO DEMOCRÁTICA. Esfera Pública e Democracia no BRasil. Idéias: Revista do Instituto de Filosofia e Ciências Humanas - Unicamp, Campinas, ano 5/6, v. 1/2, 1998-1999. 
IBGE. Perfil dos Municípios Brasileiros. Brasília: IBGE, 2009.

MARTINS, José de Souza. O Poder do atraso. São Paulo: Hucitec. 1994. NEVES, Angela Vieira. A Assistência Social: do discurso à prática profissional - as representações dos Assistentes Sociais da Legião Brasileira da Assistência. 1994. Dissertação (Mestrado em Serviço Social) - Pontifícia Universidade Católica do Rio de Janeiro, Rio de Janeiro, 1994.

. Cultura política e democracia participativa: um estudo de caso sobre o orçamento participativo. Rio de Janeiro: Gramma, 2008.

PAULA, Renato Francisco dos Santos; PAZ, Rosangela Dias Oliveira; STUCHI, Carolina Gabas (Orgs). Assistência social e filantropia: novo marco regulatório e o cenário contemporâneo de tensões entre o público e o privado. São Paulo: Giz Editorial, 2010.

PEREIRA, Luiz Carlos Bresser. Administração pública gerencial: estratégia e estrutura para um novo Estado. Brasília: MARE/ENAP, 1996.

PEREIRA, Luiz Carlos Bresser. A reforma do Estado dos anos 90: lógica e mecanismos de controle. Brasília: MARE, 1997. (Cadernos MARE da reforma do Estado, v.1).

RAICHELIS, R. Esfera pública e Conselhos de Assistência Social: caminhos da construção democrática. 2. ed. São Paulo: Cortez, 1998.

. Prefácio. In: PAULA, Renato Francisco dos Santos; PAZ, Rosangela dias Oliveira; STUCHI, Carolina Gabas (Orgs). Assistência social e filantropia: novo marco regulatório e o cenário contemporâneo de tensões entre o público e o privado. São Paulo: Giz Editorial, 2010. SALES, Teresa. Raízes da Desigualdade Social na Cultura Brasileira. Revista Brasileira de Ciências Sociais, São Paulo, n. 25, 1994.

SANTOS, Wanderley Guilherme dos. Cidadania e justiça: a política social na ordem brasileira. Rio de Janeiro: Campus, 1979.

TORRES, Iranildes Caldas. As primeiras damas e a assistência social: relações de gênero e poder. São Paulo: Cortez, 2002. 